LOGES, V.; LEMOS, M.A.; RESENDE, L.V.; MENEZES, D.; CANDEIA, J.A.; SANTOS, V.F. das. Caracteres de produção da cebola associados à resistência a tripes. Horticultura Brasileira, Brasília, v.22, n.4, p.771-774, out-dez 2004.

\title{
Caracteres de produção da cebola associados à resistência a tripes
}

\author{
Vivian Loges ${ }^{1}$; Margarida A. Lemos ${ }^{1}$; Luciane V. Resende ${ }^{1}$; Dimas Menezes ${ }^{1}$; Jonas A. Candeia ${ }^{2}$; Venézio \\ Felipe dos Santos ${ }^{2}$ \\ ${ }^{1}$ UFRPE, Depto. Fitotecnia, Av. D. Manoel de Medeiros, s/n, 52171-900 Recife-PE; E-mail: vloges@yahoo.com; ${ }^{2}$ IPA, Av. Gal. San \\ Martim, 1371, 50761-000 Recife-PE; E-mail: ipa@ipa.br.
}

\section{RESUMO}

A variabilidade existente para caracteres de produção associados à resistência a Thrips tabaci (Thysanoptera: Thripidae) foi estimada em 62 progênies de meios irmãos da cv. de cebola ValeOuro IPA-11. As testemunhas foram as cvs. ValeOuro IPA-11 e os seus genitores Roxa IPA-3 e Belém IPA-9. O experimento foi conduzido em condições de campo, em Juazeiro (BA), utilizando delineamento experimental de blocos ao acaso, com três repetições, 65 tratamentos. As estimativas dos parâmetros para as progênies de ValeOuro IPA-11 indicaram forte interferência ambiental para todos os caracteres. As maiores estimativas das herdabilidades e o ganhos esperados com $20 \%$ de pressão de seleção foram, respectivamente, de $35,74 \%$ e $10,39 \%$ para produção de bulbos comerciais (PBC), de $31,33 \%$ e $-24,48 \%$ para porcentagem de plantas improdutivas (\%I), de $33,92 \%$ e $-16,80 \%$ para produção de bulbos não comerciais (PBNC) e de $30,31 \%$ e $-13,18 \%$ para porcentagem de bulbos não comerciais (\%BNC). Estes caracteres indicaram maior possibilidade de sucesso com a seleção. O caráter ninfas de T. tabaci nas duas folhas centrais completamente desenvolvidas (NINFA), apresentou coeficientes de herdabilidade de 18,24 e $21,34 \%$ e ganho esperado de seleção de $-11,22$ e $-7,41 \%$ aos 48 e 69 dias após o transplante (DAT), respectivamente, indicando ganhos superiores em seleções efetuadas aos 69 DAT. Apesar da infestação média de 31,96 NINFA, $45,16 \%$ das progênies de ValeOuro IPA-11 apresentaram PBC acima da média, sugerindo que o tipo de resistência envolvida venha a ser por tolerância.

Palavras-chave: Allium cepa, Thrips tabaci, herdabilidade, parâmetros genéticos, tolerância, resistência de plantas.

\section{ABSTRACT}

Yield characters in onion associated to thrips resistance

The variability of yield characters associated to Thrips tabaci (Thysanoptera: Thripidae) resistance was estimated in 62 half-sib progenies of onion cv. ValeOuro IPA-11. The controls were the cvs. ValeOuro IPA-11 and the parentals Roxa IPA-3 and Belém IPA-9. The experiment was conducted in field conditions, in Juazeiro, Bahia State, Brazil, following a complete randomized block design, with three replications. The estimates of the parameters from the population of ValeOuro IPA-11 demonstrated high enviromental influence for all characters. The highest estimates of herdability and expected gain with $20 \%$ of selection pressure were, respectively, $35.74 \%$ and $10.39 \%$ for the production of commercial bulbs (PBC), $31.33 \%$ and $-24.48 \%$ for percentage of unproductive plants (\% I), $33.92 \%$ and $-16.80 \%$ for production of non commercial bulbs (PBNC) and $30.31 \%$ and $-13.18 \%$ for percentage of non commercial bulbs (\%BNC). These characters seem to indicate better possibility of genetic progress with the selection. The characters mean infestation of immature $T$. tabaci on the two completely developed inner leaves (NINFA) present herdability of 18.24 and $21.34 \%$ and expected gain with $20 \%$ of selection pressure of 18.24 and $-11.22 \%$ at 48 and 69 days after transplanting (DAT), respectively, indicating superior gains in selections at 69 DAT. Although NINFA were 31.96 insects, $45.16 \%$ of ValeOuro IPA-11 progenies demonstrated PBC values above the average, suggesting that tolerance may be the resistance mechanism.

Keywords: Allium cepa, Thrips tabaci, herdability, genetic parameters, tolerance, plant resistance.

(Recebido para publicação em 16 de setembro de 2003 e aceito em 13 de setembro de 2004)

$\mathrm{D}$ ntre os fatores que causam baixos rendimentos na cultura da cebola estão as infestações do tripes Thrips tabaci Lind. (Thysanoptera: Thripidae). A utilização de cultivares de cebola menos suscetíveis ao ataque do tripes é uma das formas mais viáveis de reduzir seus prejuízos. A resistência de genótipos foi estudada por Ramiro (1972), Coudriet et al. (1979), Domingues e Boiça Junior (1987), porém não foram avaliados os parâmetros genéticos para os caracteres envolvidos, limitando os trabalhos de melhoramento. Poucos são os trabalhos sobre este assunto, destacando-se os de Jones et al. (1935), Jones e Mann (1963) e Hamilton et al. (1999).
Candeia et al. (1998) observaram que a cv. ValeOuro IPA-11 apresentou folhagem mais resistente aos danos por tripes, porém, o tipo e causas da resistência a esta praga não foram bem esclarecidos. Esta cultivar, liberada em 1997 pelo IPA para a região semi-árida do Nordeste, foi obtida pelo cruzamento da cv. Roxa IPA-3 com a cv. Belém IPA-9, após oito ciclos de seleção massal. Apresenta folhas de coloração verde escuro e muito cerosas, com elevada produtividade (Candeia et al., 1997). Assim, o objetivo deste trabalho foi estimar a variabilidade genética de caracteres de produção em progênies de cebola cv. ValeOuro IPA-11, associados à resistência a $T$. tabaci.

\section{MATERIAL E MÉTODOS}

O experimento foi conduzido de julho a dezembro de 1998 em Juazeiro (BA). Foram avaliadas 62 progênies de meios irmãos de cebola da cv. ValeOuro IPA-11, obtidas a partir da colheita de sementes de plantas individuais, tomadas ao acaso, em campo de produção de sementes da Estação Experimental da IPA, em Serra Talhada (PE). Utilizaramse como testemunhas as cultivares ValeOuro IPA-11 e os seus genitores, Roxa IPA-3 e Belém IPA-9, totalizando 65 tratamentos. O delineamento experimental foi de blocos ao acaso, com três repetições. 
Tabela 1. Níveis de variabilidade nas cultivares e em 62 progênies de meios irmãos de cebola ValeOuro IPA-11e classificação quanto ao grau de resistência a tripes para oito caracteres. Juazeiro (BA), UFRPE, 1998.

\begin{tabular}{|c|c|c|c|c|c|c|c|c|}
\hline & \multicolumn{2}{|c|}{ Peso de bulbos $\left(\mathrm{kg} / 8,5 \mathrm{~m}^{2}\right)$} & \multirow{2}{*}{$\begin{array}{l}\text { Peso médio } \\
\text { bulbo (g) } \\
\text { (PMBC) }\end{array}$} & \multirow[b]{2}{*}{$\begin{array}{c}\text { Plantas } \\
\text { improdutivas } \\
\text { (\% I) }\end{array}$} & \multicolumn{2}{|c|}{$\%$ bulbos } & \multicolumn{2}{|c|}{ Ninfas nas folhas centrais } \\
\hline & $\begin{array}{c}\text { não } \\
\text { comerciais } \\
\text { (PBNC) }\end{array}$ & $\begin{array}{l}\text { comerciais } \\
\text { (PBC) }\end{array}$ & & & $\begin{array}{c}\text { não } \\
\text { comerciais } \\
(\% \text { BNC) }\end{array}$ & $\begin{array}{c}\text { comerciais } \\
(\% \mathrm{BC})\end{array}$ & $\begin{array}{c}48 \text { dias } \\
\text { (NINFA } 48 \\
\text { DAT) }\end{array}$ & $\begin{array}{c}69 \text { dias } \\
\text { (NINFA } 69 \\
\text { DAT) }\end{array}$ \\
\hline $\begin{array}{l}\text { Cultivares } \\
\text { (Testemunha) }\end{array}$ & \multicolumn{8}{|c|}{ Média \pm erro padrão } \\
\hline ValeOuro IPA-11 & $0,69 \pm 0,18$ & $6,09 \pm 2,01$ & $72,2 \pm 7,23$ & $2,53 \pm 0,25$ & $25,90 \pm 3,38$ & $71,57 \pm 3,26$ & $11,67 \pm 4,59$ & $27,00 \pm 5,83$ \\
\hline Roxa IPA-3 & $0,84 \pm 0,09$ & $6,41 \pm 0,29$ & $65,8 \pm 4,21$ & $8,58 \pm 1,87$ & $25,94 \pm 2,83$ & $65,49 \pm 4,43$ & $5,47 \pm 2,11$ & $41,93 \pm 7,67$ \\
\hline Belém IPA-9 & $1,25 \pm 0,06$ & $5,55 \pm 1,52$ & $61,4 \pm 4,27$ & $5,12 \pm 2,66$ & $35,05 \pm 3,71$ & $59,83 \pm 6,35$ & $10,27 \pm 2,37$ & $44,00 \pm 7,10$ \\
\hline Progênies & \multicolumn{8}{|c|}{ Valor da característica } \\
\hline ValeOuro IPA-11 & $0,75 \pm 0,04$ & $8,66 \pm 0,24$ & $75,90 \pm 1,67$ & $3,11 \pm 0,29$ & $20,38 \pm 0,86$ & $76,52 \pm 1,04$ & $7,84 \pm 0,54$ & $31,96 \pm 1,10$ \\
\hline Roxa IPA-3 & 0,24 & 4,43 & 58,4 & 0,2 & 7,63 & 61,57 & 1,47 & 10,87 \\
\hline Belém IPA-9 & 1,59 & 13,45 & 149,5 & 10,95 & 34,78 & 91,73 & 19,33 & 51,33 \\
\hline $\begin{array}{l}\text { Classificação } \\
\text { quanto à } \\
\text { resistência }\end{array}$ & \multicolumn{8}{|c|}{ Freqüência (\%) } \\
\hline $\begin{array}{l}\text { Moderadamente } \\
\text { resistente }\end{array}$ & 43,55 & 45,16 & 29,03 & 51,61 & 48,39 & 45,16 & 53,23 & 33,87 \\
\hline Suscetível & 16,13 & 12,9 & 24,19 & $, 22,58$ & 11,29 & 16,13 & 11,29 & 25,81 \\
\hline $\begin{array}{l}\text { Altamente } \\
\text { suscetível }\end{array}$ & 40,32 & 41,94 & 46,77 & 25,81 & 40,32 & 38,71 & 35,48 & 40,32 \\
\hline
\end{tabular}

As mudas foram transplantadas 37 dias após a semeadura, em espaçamento de 0,20 x 0,15 m, com ausência de seleção para tamanho de plantas. A parcela foi constituída por um leirão com 8,5 $\mathrm{m}$ de comprimento e 1,0 $\mathrm{m}$ entre sulcos de irrigação, contendo duas fileiras de plantas. A irrigação foi feita por sulcos de infiltração e os demais tratos culturais foram os adotados na região, porém sem o uso de agrotóxicos após o transplantio.

O número de ninfas nas duas folhas centrais completamente desenvolvidas foi avaliado aos 48 e 69 dias após o transplantio (DAT), adotando metodologia de Loges et al. (2000). Espécimes do tripes foram coletadas e enviadas para identificação indicando a ocorrência apenas da espécie T. tabaci L.

A colheita foi realizada aos 93 DAT quando $50 \%$ das plantas apresentaram o tombamento da folhagem. Todas as plantas da parcela (8,5 m de comprimento), foram acondicionadas em sacos telados e levadas para local sombreado e bem arejado. Após o período de dois dias de cura foram eliminadas as raízes e folhas para avaliação dos seguintes caracteres: 1) produção de bulbos não comerciais (PBNC) em kg/parcela (bulbos com diâmetro inferior a $40 \mathrm{~mm}$ ); 2) produção de bulbos comerciais (PBC) em kg/parcela (bulbos com diâmetro maior ou igual a $40 \mathrm{~mm}$ ); 3) peso médio de bulbos comerciais (PMBC) em $\mathrm{g}$ (peso total de bulbos comerciais dividido pelo número de bulbos comerciais); 4) porcentagem de plantas improdutivas (\% I) (plantas sem formação de bulbos em relação ao número de plantas sobreviventes); 5) porcentagem de bulbos não comerciais (\%BNC) (bulbos não comerciais em relação ao número de plantas sobreviventes); 6) porcentagem de bulbos comerciais (\%BC) (bulbos comerciais em relação ao número de plantas sobreviventes).

A análise estatística foi efetuada segundo o modelo matemático de Vencovsky e Barriga (1992), utilizando o programa GENES (Cruz, 1997). O ganho esperado com $20 \%$ de pressão de seleção foi calculado seguindo metodologia de Cruz e Regazzi (1997).

As progênies foram classificadas quanto ao grau de resistência a tripes com base no intervalo de confiança (IC) ao nível de $95 \%$. Para PBC, PMBC e $\%$ BC foram classificados em: moderadamente resistentes (MR) quando a média foi maior que o IC; suscetível (S) para média dentro do IC; altamente suscetível (AS) quando a média foi menor que o IC. Para os caracteres PBNC, \%I, $\%$ BNC e NINFA, os tratamentos foram classificados de forma inversa (adaptado por Barros, 1998).

\section{RESULTADOS E DISCUSSÃO}

Foram detectadas diferenças significativas entre as progênies de meios irmãos da cv. ValeOuro IPA-11 para todos os caracteres, com exceção do PMBC, \%BC e NINFA aos 48 e 69 DAT. As progênies apresentaram valores superiores aos das testemunhas, cvs. Roxa IPA-3 e Belém IPA-9, para os caracteres $\mathrm{PBC}, \mathrm{PMBC}$ e \% BC e inferiores para PBNC, \%I, \%BNC e NINFA aos 69 DAT. Aos 48 DAT, 53,23\% das progênies foram moderadamente resistentes para o caráter NINFA porém aos 69 DAT apenas $33,87 \%$ das progênies mantiveram este comportamento (Tabela 1). Considerando os caracteres PBNC, PBC, \%I, \%BNC e \%BC, verificou-se que mais de $43 \%$ das progênies de ValeOuro IPA-11 foram moderadamente resistentes a tripes, apesar da infestação média de 31,96 NINFA aos 69 DAT. Estes resultados sugerem que estas progênies sejam resistentes por tolerância em razão de terem apresentado produção acima da média mesmo com elevada infestação. Candeia et al. (1998) observaram que a cv. ValeOuro IPA-11 apresentou folhagem mais resistente aos 
Tabela 2. Estimativas de parâmetros genéticos e fenotípicos para caracteres associados à produção em 62 progênies de meios irmãos de cebola ValeOuro IPA-11. Juazeiro (BA), UFRPE, 1998.

\begin{tabular}{|c|c|c|c|c|c|c|c|c|}
\hline \multirow[b]{2}{*}{ Parâmetros } & \multicolumn{2}{|c|}{ Peso de bulbos $(\mathrm{kg} / 8,5 \mathrm{~m} 2)$} & \multirow[b]{2}{*}{$\begin{array}{l}\text { Peso médio } \\
\text { bulbo (g) } \\
\text { (PMBC) }\end{array}$} & \multirow[b]{2}{*}{$\begin{array}{c}\text { Plantas } \\
\text { improdutivas } \\
(\% \mathrm{I})\end{array}$} & \multicolumn{2}{|c|}{$\%$ bulbos } & \multicolumn{2}{|c|}{ Ninfas nas folhas centrais } \\
\hline & $\begin{array}{c}\text { não } \\
\text { comerciais } \\
\text { (PBNC) }\end{array}$ & $\begin{array}{l}\text { comerciais } \\
\text { (PBC) }\end{array}$ & & & $\begin{array}{c}\text { não } \\
\text { comerciais } \\
(\% \text { BNC })\end{array}$ & $\begin{array}{c}\text { comerciais } \\
(\% \mathrm{BC})\end{array}$ & $\begin{array}{c}48 \text { dias } \\
\text { (NINFA } 48 \\
\text { DAT) }\end{array}$ & $\begin{array}{c}69 \text { dias } \\
\text { (NINFA } 69 \\
\text { DAT) }\end{array}$ \\
\hline $\mathrm{s} 2 \mathrm{f}$ & 0,09 & 3,57 & 0,00 & 0,27 & 0,55 & 30,66 & 1,84 & 3,51 \\
\hline $\mathrm{s} 2 \mathrm{e}$ & 0,06 & 2,30 & 0,00 & 0,18 & 0,38 & 22,47 & 0,69 & 0,85 \\
\hline s2g & 0,03 & 1,28 & 0,00 & 0,08 & 0,17 & 8,20 & 0,08 & 0,14 \\
\hline h2m (\%) & 33,92 & 35,74 & 23,13 & 31,33 & 30,31 & 26,73 & 18,24 & 21,34 \\
\hline CVg (\%) & 23,27 & 12,95 & 8,31 & 17,45 & 9,43 & 4,61 & 12,11 & 6,94 \\
\hline CVe (\%) & 56,26 & 30,06 & 26,22 & 44,75 & 24,78 & 13,21 & 35,85 & 17,06 \\
\hline b1 & 0,41 & 0,43 & 0,32 & 0,39 & 0,38 & 0,35 & 0,34 & 0,41 \\
\hline Gs (\%) & $-16,80$ & 10,39 & 5,38 & $-24,48$ & $-13,18$ & 3,55 & $-11,22$ & $-7,41$ \\
\hline
\end{tabular}

$\sigma_{\mathrm{f}}^{2}-$ variância fenotípica; $\sigma_{\mathrm{e}}^{2}-$ variância ambiental; $\sigma_{\mathrm{g}}^{2}-$ variância genética; $\mathrm{h}^{2} \mathrm{~m}(\%)$ - Coeficiente de herdabilidade no sentido amplo; $\mathrm{CV}$ (\%) - Coeficiente de variação genético; $\mathrm{CV}_{\mathrm{e}}(\%)$ - Coeficiente de variação experimental; b $\mathrm{b}_{1}$ - relação entre $\mathrm{CV}_{\mathrm{g}}$ e $\mathrm{CV}_{\mathrm{e}}$; $\mathrm{Gs}(\%)$ - $\mathrm{Ganho}^{\mathrm{g}}$ genético esperado com uma intensidade de seleção de $20 \%$.

danos por tripes e vale salientar que um dos seus genitores, a cv. Roxa IPA-3, apresentou tolerância a tripes segundo Candeia et al. (1997) e Hamilton et al. (1999).

A grande diferença no grau de resistência a tripes e demais caracteres avaliados entre as progênies da cv. ValeOuro IPA-11, demonstram existir variabilidade que ainda pode ser explorada.

As herdabilidades observadas foram baixas (Tabela 2). De acordo com Borém (1997), avaliações conduzidas em ambientes com condições adversas e caracteres avaliados em períodos longos são mais influenciados pelo ambiente, acarretando estimativas de herdabilidade menores. É importante ressaltar que os caracteres associados à produção foram avaliados 93 dias após o transplantio, em um cultivo sob condições de estresse devido à alta população do tripes.

Os valores do índice $b_{1}$ (relação entre $\mathrm{CV}_{\mathrm{g}}$ e $\mathrm{CV}_{\mathrm{e}}$ ) foram menores que 0,5 para os caracteres avaliados, indicando a elevada interferência do ambiente. Para minimizar os efeitos do ambiente nas estimativas dos parâmetros genéticos destes caracteres, sugere-se o aumento do número de repetições e de ambientes avaliados.

$\mathrm{O}$ caráter PBC apresentou herdabilidade $35,74 \%$, coeficiente de variação genético $12,95 \%$ e ganho esperado de $10,39 \%$, aplicando-se $20 \%$ de intensidade de seleção. Estes valores indicam moderada condição de progresso na sua seleção. Para esse mesmo caráter, McCollum (1966) observou herdabilidades entre 0 e $11 \%$ em cinco populações de cebola e, em outro experimento, a herdabilidade em dez populações originadas de quatro cultivares variou de 0 a 23\% (McCollum, 1971). Já Buso (1978) obteve herdabilidades de 41,64 e $67,63 \%$ e ganho esperado de 13,96 a $19,41 \%$, aplicando-se $10 \%$ de intensidade de seleção em população $\mathrm{C}_{5}$ do cruzamento das cultivares Baia e Red Creole. Candeia et al. (1986) registraram herdabilidade de $65,06 \%$, com coeficiente de variação genético $12,47 \%$, ambos avaliados com dados de parcela em progênies da cultivar Pira Tropical.

Porcentagem e peso de bulbos comerciais são características que podem ser tomadas como indicativo da capacidade produtiva de uma cultivar (Candeia et al., 1986). A possibilidade de elevar a produção das progênies avaliadas pela seleção direta de \%BC e PMBC apresenta-se moderada devido aos baixos valores da herdabilidade para estes caracteres $(26,73$ e $23,13 \%$, respectivamente), associados ao pequeno coeficiente de variação genético $(4,61$ e $8,31 \%$, respectivamente), ganho esperado de seleção $(3,55$ e $5,38 \%$, respectivamente) e índice $b_{1}(0,35$ e 0,32 , respectivamente). Buso (1978) registrou herdabilidade de 2,31 e 13,42\% para número de bulbos comerciais (avaliados com total de parcela), valores inferiores aos observados, e de 39,09 e 12,01\% para peso de bulbo (avaliado em plan- tas individuais). Já Candeia et al. (1986), registraram herdabilidades de 50,01\% para porcentagem de bulbos comerciais (avaliados com total de parcela) e de $44,49 \%$ para peso de bulbo (avaliado em plantas individuais) e Carvalho (1996), em 90 progênies de meios irmãos da cultivar Belém IPA-9, obteve herdabilidades de $76,72 \%$ para número de bulbos comerciais e de 59,53\% para peso de bulbo (avaliados com total de parcela), valores muito superiores aos observados.

Os caracteres PBNC, \%I e \%BNC são indesejáveis, ocorrendo quando a planta consegue sobreviver, porém não forma bulbo comercial, contribuindo para a redução da produtividade. São caracteres muito influenciados pelo ambiente como suprimento de nitrogênio, fotoperíodo, temperatura mínima para bulbificação, espaçamento (Jones e Mann, 1963; Brewster, 1994) e elevadas infestações de tripes (Sato, 1989). Os caracteres PBNC, \% I e \%BNC apresentaram coeficientes de herdabilidade de 33,$92 ; 31,33$ e $30,31 \%$, respectivamente. Herdabilidades superiores foram estimadas em outras populações de cebola para o caráter \% I por Buso (1978) de 39,92 e $52,39 \%$, por Candeia et al. (1986) de 65,25\% e para número de plantas improdutivas e \%BNC por Carvalho (1996) de 64,82\% e 43,25\%. Para estes caracteres, o valor de $b_{1}$ foi 0,41 ; 0,39 e 0,38 , respectivamente, e o progresso de seleção esperado com $20 \%$ de intensidade de seleção foi $-16,80 \%$, $-24,48 \%$ e $-13,18 \%$, respectivamente. 
O caráter NINFA apresentou coeficientes de herdabilidade de 18,24 e $21,34 \%$ e ganho esperado de seleção de $-11,22$ e $-7,41 \%$ aos 48 e 69 DAP, respectivamente. Hamilton et al. (1999), ao avaliarem a população resultante do cruzamento das cultivares Roxa IPA-3 e TG1015Y, obtiveram valores para resistência ao tripes de 5,30 e 4,00\% para herdabilidade restrita e de 4,10 e 8,00\% para a ampla, considerando-os muito baixos. Esses autores afirmaram que uma planta pode apresentar menos insetos devido à resistência genética ou a forma de dispersão do inseto, e que este fato explicou a baixa herdabilidade.

A produção apresentada pelas progênies de ValeOuro IPA-11 surpreenderam, pois não se esperava que na região do Submédio São Francisco, devido à elevada população de tripes, fosse possível cultivar cebola sem a aplicação de defensivos. As progênies de ValeOuro IPA-11 que apresentaram produção acima da média, apesar das altas infestações de tripes, indicaran que nível de tolerância pode estar ocorrendo, porém sem descartar outros mecanismos como não-preferência observada em outros cultivares de cebola (Loges et al., 2004) ou antibiose. Pode-se dizer que a população de ValeOuro IPA-11 apresenta ainda variabilidade residual que permite moderado progresso genético, dirigindo-se a seleção principalmente para o aumento de PBC e para a redução da PBNC, \%I, \%BNC e NINFA com a seleção realizada aos 69 DAT.

\section{AGRADECIMENTOS}

Os autores agradecem à FACEPE, ao IPA, ao Eng. Agrônomo Jarbas
Florentino de Carvalho, a todos da Fazenda Rodeador, a Renata C. Monteiro pela identificação das amostras de tripes e demais pessoas que contribuíram para a execução do trabalho.

\section{LITERATURA CITADA}

BARROS, R. Efeito de cultivares de repolho Brassica oleracea $L$. var capitata na biologia da traça das crucíferas, Plutella xylostella (L. 1758) e do parasitóide Trichograma pretiosum Riley, 1879. Piracicaba: ESALQ, 1998. 99 p. (Tese doutorado).

BORÉM, A. Herdabilidade. In: BORÉM, A. Melhoramento de Plantas. Viçosa: UFV, 1997. p. 89122.

BREWSTER, J.L. Onions and other vegetable alliums. Wallingford: CAB INTERNATIONAL, 1994. $236 \mathrm{p}$.

BUSO, J.A. Estimativas de parâmetros genéticos de caracteres de planta e bulbo de cebola (Allium cepa L.). Piracicaba: ESALQ, 1978. 132 p. (Tese mestrado).

CANDEIA, J.A.; SILVA, N.; ZANOTTO, M.D. Parâmetros genéticos e correlações em cebola 'Pira Tropical'. Horticultura Brasileira, Brasília, v.4, n.2, p.17-19, 1986.

CANDEIA, J.A.; MENEZES, D.; MENEZES, J.T.; MARANHÃO, E.A.A.; FRANÇA, J.G.E Cultivar de cebola amarela ValeOuro IPA-11. In: CONGRESSO BRASILEIRO DE OLERICULTURA, 37., 1997, Manaus. Anais... Manaus: SOB, 1997. p. 56.

CANDEIA, J.A.; CARVALHO, J.F.; MARANHÃO, E.A.A.; CAVALCANTI, V.A.L.B.; RODRIGUES, V.J.L.B. Avaliação do nível de resistência de populações de cebola ao tripes e ao "sapeca". In: CONGRESSO BRASILEIRO DE OLERICULTURA, 38., 1998, Petrolina. Anais... Petrolina: SOB, 1998. p. 47. 1 CD-ROM.

CARVALHO, J.F. Avaliação de progênies de meios irmãos em cebola (Allium cepa $L$.) para caracteres fitotécnicos. Recife: UFRPE, 1996. 68 p. (Tese mestrado).

COUDRIET, D.L.; KISHABA, A.N.; McCREIGHT, J.D.; BOHN, G.W. Varietal Resistance in onions to thrips. Journal of Economic Entomology, v. 72, p.614-615, 1979.
CRUZ, C.D. Programa Genes. Aplicativo computacional em genética e estatística. Viçosa: UFV, 1997. 442 p.

CRUZ, C.D.; REGAZZI, A.J. Modelos biométricos aplicados ao melhoramento genético. 2 ed. Viçosa: UFV, 1997. 390 p.

DOMINGUES, E.P.; BOIÇA JUNIOR, A.L. Observação da suscetibilidade de seis variedades de cebola ao Thrips tabaci Lindeman, 1888 (Thysanoptera-Thripidae), no "cultivo do cedo". Científica, Jaboticabal, v.15, n.1/2, p.79-84, 1987. HAMILTON, B.K.; PIKE, L.M.; SPARKS, A.N.; BENDER, D.A.; JONES, R.W.; CANDEIA, J.; FRANÇA, G. Heritability of thrips resistance in 'IPA-3' onion cultivar in South Texas. Euphytica, v.109, p.117-122, 1999.

JONES, H.A.; BAILEY, S.F.; EMSWELLER, S.L. Field studies of Thrips tabaci Lind. With especial reference to resistance in onions. Journal of Economic Entomology, v. 28, n.4, p.678-680, 1935.

JONES, H.A.; MANN, K.L. Onion and their allies. New York: Leonard Hillbooks, 1963. 286 p.

LOGES, V; LEMOS, M.A.; MENEZES, D.; BARROS, R.. Efficiency of methods for sampling thrips on onion. In: INTERNATIONAL CONGRESS OF ENTOMOLOGY, 11., 2000, Foz do Iguaçu, Anais... Foz do Iguaçu: SEB, 2000. p. 268.

LOGES, V.; LEMOS, M.A.; RESENDE, L.V.; MENEZES D.; CANDEIA, J.A.; SANTOS, V.F. DOS. Resistência de cultivares e híbridos de cebola a tripes. Horticultura Brasileira, Brasília, v.22, n.2, p.221-224, 2004.

McCOLLUM, G.D. Heritability and genetic correlation of some onion bulb traits. Estimate from S1 offspring-on-parent regression. Journal of Heredity, v.57, p.105-110, 1966.

McCOLLUM, G.D. Heritability of onion bulb shape and size. Estimate from half-sib families. Journal of Heredity, v.62, p.101-104, 1971.

RAMIRO, Z.A. Comportamento de variedades $e$ controle do Thrips tabaci, Lindeman, 1888, em culturas de cebola (Allium cepa L.). Piracicaba: ESALQ, 1972. 144 p. (Tese doutorado).

SATO, M.E. Avaliação do dano e controle do Thrips tabaci Lindeman, 1888 na cultura da cebola (Allium cepa L.). Piracicaba: ESALQ, 1989. 93 p. (Tese doutorado).

VENCOVSKY, R.; BARRIGA, P. Genética biométrica no fitomelhoramento. Ribeirão Preto: Revista Brasileira de Genética, 1992. 486 p. 